\title{
SATISFACTION LEVEL OF PATIENTS, PHYSICIANS, AND PRIVATE PRIMARY HEALTH-CARE CENTER MANAGERS WITH CHRONIC DISEASE MANAGEMENT PROGRAM IN INDONESIA
}

\author{
RANO K SINURAYA*, RIZKY ABDULAH, AJENG DIANTINI, AULIYA A SUWANTIKA \\ Department of Pharmacology and Clinical Pharmacy, Faculty of Pharmacy, Universitas Padjadjaran, Indonesia. \\ Email: r.k.sinuraya@unpad.ac.id
}

Received: 21 October 2016, Revised and Accepted: 30 January 2017

\section{ABSTRACT}

Objective: Program Pengelolaan Penyakit Kronis (PROLANIS) or Chronic Disease Management Program is a health-care system that was conducted by Healthcare and Social Security Agency in Indonesia to improve patients' quality of life. The objective of this study was to analyze the level of satisfaction of patients, physicians, and private Primary Healthcare Centers (PHCs) with this program, focusing on hypertension care.

Methods: This study was conducted in 7 private PHCs in Bandung City, Indonesia. A cross-sectional study was conducted to measure the patient satisfaction with Patient Satisfaction Questionnaire Short Form on 143 PROLANIS patients with hypertension. A total number of 8 physicians and 7 private PHC managers were involved in this study. Level of satisfaction of physicians and private PHC managers were observed using in-depth interviews.

Results: The results showed that patient satisfaction was estimated to be $68.52 \pm 8.54$, which could be interpreted that patient satisfy with PROLANIS. In-depth interviews showed that physicians did not satisfy with PROLANIS due to several factors (e.g., unintegrated prescription systems, lack of medicines, uncompleted laboratory facilities, lack of physicians, unintegrated referral services, and lack of collaboration between primary and secondary health-care system). On the other hand, private PHC managers were quite satisfied with PROLANIS due to its linearity with other activities in private PHCs.

Conclusion: Level of satisfaction of patients with PROLANIS is quite good, whereas physicians might not satisfy with this program. In particular, private PHC managers confirmed that they are satisfied with this program.

Keywords: Program Pengelolaan Penyakit Kronis, Hypertension, Satisfaction level, Patient preference.

(C) 2017 The Authors. Published by Innovare Academic Sciences Pvt Ltd. This is an open access article under the CC BY license (http://creativecommons. org/licenses/by/4. 0/) DOI: http://dx.doi.org/10.22159/ajpcr.2017.v10s2.20414

\section{INTRODUCTION}

Hypertension is a common health problem seen in the community, especially in primary care. If not detected earlier and treated appropriately, this disease can lead to heart failure, stroke, renal failure, blindness, and even death. This disease is also called silent killer with the highest prevalence in mortality worldwide [1,2].

Based on the Indonesian Basic Health Research (Riset Kesehatan Dasar) in 2013 , the prevalence of hypertension in Indonesia on age $\geq 18$ years old is about 25.8\%, the highest in Bangka Belitung (30.9\%), followed by South Kalimantan (30.8\%), East Kalimantan (29.6\%), and West Java (29.4\%) [3,4]. In 2014, Indonesian Government has conducted national health-care coverage called Badan Penyelenggara Jaminan Sosial Kesehatan (Healthcare and Social Security Agency [HSSA]). One of HSSA's programs is Program Pengelolaan Penyakit Kronis (PROLANIS) or Chronic Disease Management Program (CDMP). This program is conducted in primary health care and focused on therapy management of patient with hypertension and diabetes mellitus. CDMP is a healthcare system with proactive approach that is integrated by involving patients, doctors, pharmacists, nurses, health-care facilities, and HSSA. The activities of CDMP are medical consultation/education, home visit, reminder, activity clubs, and monitoring health status. This program is aimed to maintain the health status of the patient and to improve their quality of life effectively [5].

Every program, especially health-care program should be evaluated to improve the quality of health-care system. Unfortunately, until now, there has been no study that evaluates CDMP particularly to analyze the satisfaction level of patients, physicians, and the primary health care.

\section{METHODS}

This study was conducted in 7 private Primary Healthcare Centers (PHCs) in Bandung City, Indonesia, from November 2015 to April 2016. A cross-sectional study was conducted to measure patient satisfaction using modified Patient Satisfaction Questionnaire Short Form (PSQ-18) [6], with seven subscales of satisfaction on 143 CDMP patients with hypertension. Inclusion criteria are patient 18 years old or above, patient with hypertension and/or get hypertension medicines, member of HSSA, at least visiting PHCs four times, and the patient has one blood pressure above at least once. Exclusion criteria are hemodialysis patient, obstetrics and gynecology patient. A total number of 8 physicians and 7 private PHC managers were involved in this study. Level of satisfaction of physicians and private PHC managers were observed using a qualitative study through in-depth interviews. Statistical analysis was performed using SPSS 17.0.

\section{RESULTS}

This research was divided into two groups; there were quantitative study to measure satisfaction level of CDMP's patient and qualitative study to analyze satisfaction level of physicians and private PHS managers. This study was approved by the Ethic Committee, Faculty of Medicine, Universitas Padjadjaran, Indonesia.

\section{Patient satisfaction level study}

The modified PSQ-18 questionnaire consists of 18 questions represent the 7 subscales of satisfaction: (1) General satisfaction, (2) technical quality, (3) interpersonal manner, (4) communication, (5) financial aspects, (6) the time spent with the doctor, and (7) accessibility and 
convenience [6,7]. Before the study begins, the patient was given information about this study and also informed consent. The validity and reliability test showed that the questionnaire was valid and reliable with Cronbach's alpha for each subscale was around 0.723-0.773. Sociodemographic characteristics are summarized in Table 1.

Based on Table 1, it can be seen that, in general, the participants of CDMP were women $(\geq 50 \%)$. The educational background is dominated by high school level followed by university level. Most of the CDMP participants do not work because generally they are housewives and retired officer.

The satisfaction level of CDMP patient is about $68.52 \pm 8.54$ (Table 2). This value was a total average score of satisfaction level for all subscales of PSQ-18. Based on the results, the CDMP patient satisfaction score was ranging 59.98-77.06.

The subsequent measurement of the satisfaction of participants PROLANIS is grouped into the categories of age, gender, education, and employment (Table 3). The satisfaction level of CDMP patient based on

Table 1: Patients' sociodemographic profile

\begin{tabular}{ll}
\hline Item & $\mathbf{n}(\%)$ \\
\hline Gender & \\
Male & $44(30.8)$ \\
Female & $99(69.2)$ \\
Age (year) & \\
18-44 & $6(4.2)$ \\
$45-64$ & $108(75.5)$ \\
$65-74$ & $21(14.7)$ \\
$\geq 75$ & $8(5.6)$ \\
Level of education & \\
No formal education & $0(0)$ \\
Primary school & $29(20.3)$ \\
Middle school & $24(16.8)$ \\
High school & $59(41.3)$ \\
University & $31(21.7)$ \\
Occupation & \\
Working & $39(27.3)$ \\
Not working & $104(72.7)$ \\
\hline
\end{tabular}

sociodemographic profile is shown in Table 3 . The average satisfaction score was around 3-4 from the maximum score of five.

\section{Physicians satisfaction level study}

Satisfaction level of physicians was measured using qualitative studies to carry out the perception or perspective of emic of CDMP program in their point of view. An in-depth interview was conducted to 8 physicians focusing on 4 major factors, namely, (1) adequate time, (2) clinical freedom, (3) high-quality care, and (4) job satisfaction [9]. The selected physicians were the doctor who was dealing with CDMP patient and willing to be the participant of this study after being given an explanation about and purpose of this research. Based on the indepth interview, all of the physicians were not satisfied with CDMP because of some factors (Fig. 1).

\section{PHCs' satisfaction level study}

The participants in this study were the manager of private PHCs. Their satisfaction level was also measured using qualitative studies to carry

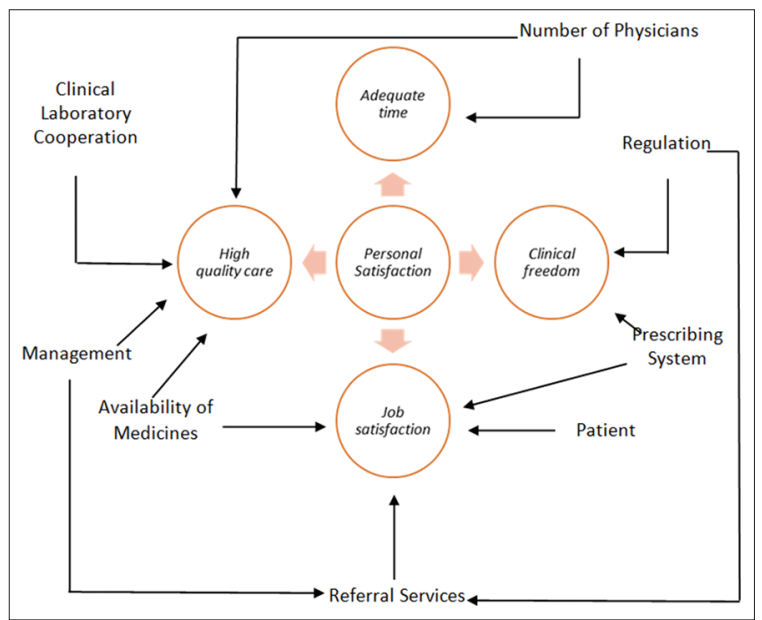

Fig. 1: Factors affecting physicians' satisfaction of Chronic Disease Management Program

Table 2: Patient satisfaction with CDMP

\begin{tabular}{ll}
\hline Subscale and item [6,8] & Mean (SD) \\
\hline General satisfaction & $7.42(1.71)$ \\
The medical care I have been receiving is just about perfect \\
I am dissatisfied with some things about the medical care I receive \\
Technical quality \\
I think my doctor's office has everything needed to provide complete care \\
Sometimes doctors make me wonder if their diagnosis is correct \\
When I go for medical care, they are careful to check everything when treating and examining me. \\
I have some doubts about the ability of the doctors who treat me \\
Interpersonal manner \\
Doctors act to businesslike and impersonal toward me \\
My doctors treat me in very friendly and courteous manner \\
Communication \\
Doctors are good about explaining the reason for medical test \\
Doctors sometimes ignore what I tell them \\
Financial aspects \\
I feel confident that I can get the medical care I need without being set back financially \\
I have to pay for more money of my medical care than I can afford \\
Time spent with doctor \\
Those who provided my medical care sometimes hurry too much when they treat me \\
Doctors usually spend plenty of time with me \\
Accessibility and convenience \\
I have easy access to the medical specialist I need \\
Where I get medical care, people have to wait too long for emergency treatment \\
I find it hard to get an appointment for medical care right away \\
I am able to get medical care whenever I need it
\end{tabular}




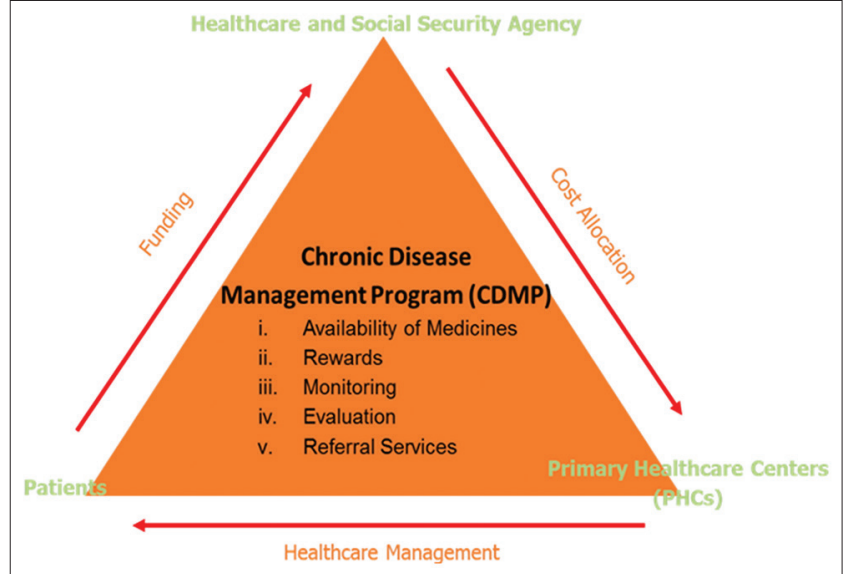

Fig. 2: Factors affecting Primary Healthcare Centers managers' satisfaction of Chronic Disease Management Program

out their perception/perspectives regarding to CDMP. An in-depth interview was performed focusing on four major factors: (1) Healthcare services, (2) capitation system in health-care program, (3) health promotion, and (4) the opportunities and challenges national health coverage in Indonesia [10].

The results showed that all of the managers were quite satisfied with CDMP, but there were same problems in every PHC during the implementation of this program such as the availability of medicines, the time to conduct CDMP, and evaluation system of HSSA (Fig. 2).

\section{DISCUSSION}

In the 7 private PHCs, CDMP is always conducted on Friday 7 am-12 pm every month. The patient will be given medicines for a month, laboratory check, blood pressure measurement, and information related their diseases. The results of this study showed that a total of 143 participants of CDMP were dominated by female with age around 45-64 years old (Table 1). In addition, participants were dominated housewives and retired officer with the percentage reached $73 \%$ of total active participants. The previous study, that was conducted by Ghazwani [11], showed that the number of membership in a health activities was influenced by several factors, for example, age, educational background, and daily activity. In general, most of the CDMP patient who regularly visits PHC was high school graduate because their working schedule was more flexible than university graduate. Senior high school graduate commonly worked as factory workers, farmer, and merchant. On the other hand, university graduate commonly works in a company, national officer, and many others job that has working time from 8 am to $4 \mathrm{pm}$. Therefore, they only come to the PHC in their free time. The percentage of elderly patients also reached more than $80 \%$ because in early 40 -year-old people become more aware about their body and health status.

Based on the data, the highest satisfaction score was in category accessibility and convenience 15.36 (2.33), technical quality 15.01 (2.50), interpersonal manner 7.83 (1.49), and communication 7.83 (1.41) followed by financial aspects 7.56 (1.63), time spent with the doctor 7.51 (1.51), and general satisfaction 7.42 (1.71). The average score of patient satisfaction level in private PHCs in Bandung was ranged 59.98-77.06 (Table 2). The previous study showed that accessibility and convenience, technical quality, interpersonal manner, and communication also have the highest score. If PHCs want to increase patient satisfaction level then they should start to identify problems related financial aspect, the time spent with the doctor, and general satisfaction [12]. For example, financial aspect became major problem for the patient. Sometimes they have to spent some money if want to get examination and it was not covered by national health coverage. In addition, sometimes patient feel uncomfortable with the

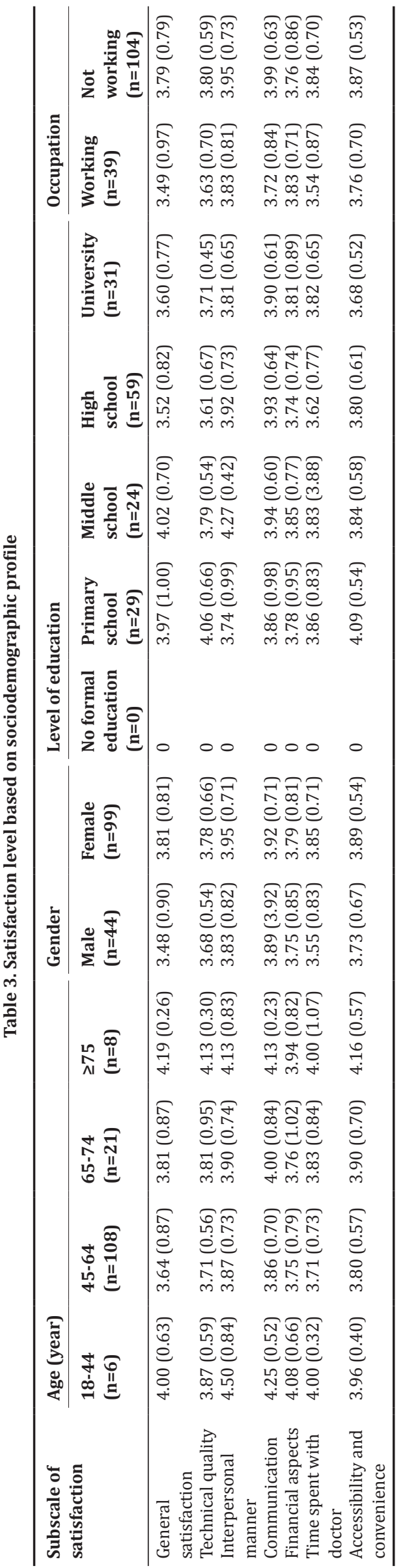


physicians because during examination sometimes the physicians impressed in hurry.

In Table 3, the correlation between levels of satisfaction and sociodemographic showed that there was no really difference in score for each age subcategory to the total satisfaction score. In general, every subscale was ranging 3.7-4.5 with maximum score of five. This finding is almost same as the previous study when converted in percentage, level of satisfaction reached $60-70 \%$. However, if looked specifically, the patient who had the highest satisfaction score was female in the age range of $\geq 75$ years and 18-44 years [13]

The CDMP patient who demonstrated the highest level of satisfaction was high school graduate, while in based on working status the highest satisfaction score was in the group "do not work" (housewives, retirees, and do not work at all). Alotaibi et al. [14] found statistically significant differences of patients' responses to a health-care program over the age, gender, level of education, and working status. In this study, it also happened because the working people generally found that it was difficult to follow the schedule of CDMP. Some respondents said that sometimes they did not routinely follow the activities of CDMP because it was held on weekdays or their working schedule. In addition, participants also complained about the laboratory examination schedule between and control to the doctor. From these points, every PHC have to evaluate their management in CDMP related to paying system and also schedule of CDMP. It will improve patient satisfaction and quality of life of patients can also be optimized. Systems management and services (hospitality, facilities, and human resources) are the main focus to be followed up in the future.

In the physician satisfaction, the in-depth interview was performed to doctor who manages CDMP patient in private PHCs. The interview was focused on adequate time, clinical freedom, high-quality care, and job satisfaction (Fig. 1) $[9,15]$. Based on the results of the interview, doctors generally felt CDMP was very good because they can control directly and evaluate the condition of the patient. CDMP ensured that the patients will come regularly every month to follow the activities such as blood pressure measurement and taking medicines. Doctors find it easier to conduct monitoring of the patient's health condition and efficient because it is done once a month. Until today, there are not parameters to evaluate whether CDMP is effective or not. However, when viewed from the patients' clinical outcomes then this program event was felt quite effective because the patient's blood pressure can be controlled periodically to keep it stable.

Some perspectives were gained from the interview it was stated that the activities of CDMP were not optimal because it was not supported by a good system, for example, laboratory results and availability of medicines. Scheurer et al. [16] also found the same problems about facilities. Physicians said that CDMP can be done only in 1 day, but because the laboratory result did not come out in the same day so the doctor have to examine the patient the other day. Commonly the patient did not come exactly the other day, sometimes they came 3 days or next week after the laboratory results came out. This problem can be a factor that decreases patient adherence and make their disease uncontrolled.

The other problem was the availability of medicines in the clinic or pharmacy. Sometimes patient have to come the other day to take their medicines. Moreover, they have to buy their own medicine until the CDMP' medicines are available. The physicians thought there were some uncooperative systems between NSSA and PHCs. A synergistic is needed to improve a system quality in health care, for example, good facilities, medicines management supply, and even patient queueing system. The same problems were stated by Djuhaeni and Gondodiputro, [17] that to achieve an optimal health services there should be synergy from input, process, and output particularly in human resources, management, funding, infrastructure systems, supplies, and community needs.
The other obstacle was inadequate of medical doctor in a primary care. When there were many patients but only few doctors available, sometimes the doctor felt not have enough time to examine their patient. Therefore, some doctors still felt not satisfied from the aspect of high-quality care and adequate time.

The other assessment aspects are job satisfaction and clinical freedom. In general, physicians felt not satisfied with these two aspects. This was because the referral system did not work properly and the patient did not follow the referral rules too [18]. The finding showed that in PHCs, people came to primary care to ask referral letter to hospital without doing any examination in the primary care, even it is just coughs, colds, flu, fever, or ordinary colds but directly patients asking for referral to secondary health facilities.

The study that conducted by Bleich et al. [19] reported that satisfaction level of primary care was depended on national coverage, patient experience, patient expectation, and reward from policy makers. The results of in-depth interview with PHCs managers were delivered in a triangle health scheme (Fig. 2). As in the picture, the health system was formed by the HSSA, health facilities (in this research is PHC), and the patients themselves. A synergy of this factor has to balance so that the system can run well. Based on the results of this study, the manager was quite satisfied with CDMP because they can play an active role with CDMP because it is simpler, patient got free medical treatment, and patient also came to $\mathrm{PHC}$ regularly.

However, sometimes the activities of CDMP felt still less optimal because its implementation was fairly short (from 7 am to $12 \mathrm{pm}$ ) and once a month. CDMP is linear with the official program of primary health care in Indonesia. There are promotive, preventive, curative, and also rehabilitative. Through CDMP, PHCs can do health promotion not only in hypertension but also other education such as hygiene, healthy food, and regular exercise [20,21].

PHC generally has no problem with the capitation system which has been established by government. However, the obstacles were the availability of medicines in the pharmacy so that sometimes doctors prescribed medicines which not in the HSSA' catalogue. The last obstacle was the schedule of CDMP, commonly CDMP was held on weekdays so that there were few patients came to control routinely, and all of these problems also affected the level of satisfaction of patients and physicians as mentioned before. Therefore, PHC should improve their performance, for example, managerial aspects, facilities, and services. However, by the presence of this challenge gives positive values to encourage collaboration with the private PHC and HSSA.

\section{CONCLUSIONS}

Level of satisfaction of patients with CDMP is quite good, whereas physicians might not satisfy with this program. In particular, private PHC managers confirmed that they are satisfied with this program.

\section{ACKNOWLEDGMENT}

The researchers thank all master degree students in clinical pharmacy Universitas Padjadjaran (batch 2013-2015) who helped to collect the data. We also thank Mr. Azhar for statistical analysis assistance.

\section{REFERENCES}

1. Ayala C, Greenlund K, Croft J, Neff L, Dai S, Zheng Z, et al. Statespecific trends in self-reported blood pressure screening and high blood pressure. United States 1991-1999. Morb Mortal Wkly Rep 2012;51(21):456.

2. James PA, Oparil S, Carter BL, Cushman WC, Dennison-Himmelfarb C, Handler J, et al. 2014 evidence-based guideline for the management of high blood pressure in adults: Report from the panel members appointed to the eighth joint national committee (JNC 8). JAMA 2014;311(5):507-20.

3. Ministry of Health of Indonesia. Indonesian Basic Health Research. Jakarta: Ministry of Health of Indonesia; 2013. 
4. Department of Health of Bandung City. Health Profile of Bandung City, Indonesia. Bandung: Department of Health of Bandung City; 2012.

5. HSSA. Chronic Disease Management Program in Indonesia; 2014. Available from: http:/www.bpjs-kesehatan.go.id/bpjs/ dmdocuments/06-PROLANIS.pdf.

6. Marshall G, Hays R. The Patient Satisfaction Questionnaire Short Form (PSQ-18). Sata Monica, CA: RAND Health; 1994.

7. Thayaparan A, Mahdi E. The patient satisfaction questionaire short form (PSQ-18) as an adaptable, reliable, and validated tool for use in various setting. Med Educ 2013;18:21747.

8. Grogan S, Conner M, Norman P, Willits D, Porter I. Validation of a questionnaire measuring patient satisfaction with general practitioner services. Qual Health Care 2000;9:201-15.

9. Tyssen R, Palmer KS, Solberg IB, Voltmer E, Frank E. Physicians' perceptions of quality of care, professional autonomy, and job satisfaction in Canada, Norway, and the United States. BMC Health Serv Res 2013;13:516.

10. Mboi N. Indonesia: On the way to universal health care. Health Syst Reform 2015;1(2):91-7.

11. Ghazwani EY, Al-Jaber OA. Study of satisfaction of diabetic patients attending the diabetes clinic at primary health care centers in Abha city, Saudi Arabia. Int J Med Sci Public Health 2014;3(4):436-43.

12. Ganasegeran K, Perianayagam W, Manaf R, Jadoo S, Al-Dubai S. Patient satisfaction in Malaysia's busiest outpatient medical care. Sci World J 2015;2015:1-6.
13. Mohamed EY, Sami W, Alotaibi A, Alfarag A, Almutairi A, Alanzi F. Patients' satisfaction with primary health care centers' services, Majmaah, Kingdom of Saudi of Saudi Arabia. Int J Health Sci (Qassim) 2015;9(2):163-70.

14. Alotaibi M, Alazemi T, Alazemi F, Bakir Y. Patient satisfaction with primary health-care services in Kuwait. Int J Nurs Pract 2014;21(3):249-57.

15. Van-Ham I, Verhoeven A, Groenier K, Groothoff JW, de Haan J. Job satisfaction among general practitioners: A systematic literature review. Eur J Gen Pract 2006;12(4):174-80.

16. Scheurer D, McKean S, Miller J, Wetterneck T. U.S. Physician satisfaction: A systematic review. J Hosp Med 2009;4:560-8.

17. Djuhaeni H, Gondodiputro S. Health Economic. Bandung: Faculty of Medicine, Universitas Padjajdaran; 2012.

18. Grembowski D, Ulrich CM, Paschane D, Diehr P, Katon W, Martin D, et al. Managed care and primary physician satisfaction. J Am Board Fam Med 2003;16(5):383-93.

19. Bleich SN, Özaltin E, Murray CJ. How does satisfaction with the health-care system relate to patient experience? Bull World Health Organ 2008;87:271-8.

20. President Regulation No. 111 of 2013 on The Amendment of President Regulation No. 12 of 2013 on Health Care Security; 2013.

21. UU 40/2004 Tentang Sistem Jaminan Social Nasional (SJSN). Law 40/2004 on the National Social Security System; 2014. 